were performed on 10 arthritis patients. The resulting arthritis treatment satisfaction (ARTS) questionnaire comprised 24 items.

Validation study: Psychometric analysis was performed to establish the structure (Principal Component Analysis (PCA) and multi-trait analysis) and the internal consistency (Cronbach alpha) of the questionnaire on a cross-sectional sample of 797 arthritis patients recruited by their clinicians. Patients were on average 67.5 years old (sd $=10.4), 64.5 \%$ were women, $26 \%$ had arthritis of the hip, 58\%had arthritis of the knee, and all patients had suffered from arthritis for an average of 7 years (sd $=6.4$ ).

Results PCA revealed a clear four dimensional structure. In order to reduce the number of items, 6 out of the 24 items were discarded because of moderate to low item convergent validity, and because they did not modify the internal reliability coefficient and content validity of the questionnaire. The final questionnaire comprised 18 items consisting of 4 dimensions measuring treatment advantages, treatment convenience, apprehensions about treatment and satisfaction with medical care. Item convergent and discriminant validity and the internal consistency reliability were satisfactory (Cronbach alpha of 0.84 for the global questionnaire which varied between 0.63 and 0.88 per dimension). PCA and multitrait analysis were reproduced on an independent sample of 137 patients, thus confirming the relevance of the 4 dimensional structure and internal consistency reliability of the questionnaire.

Conclusion Psychometric validity of this first treatment satisfaction questionnaire specific to arthritis is promising and further psychometric validation (clinical validity and reproducibility) is presently underway.

\section{SAT0085 MELOXICAM HAS A LOW RISK OF SERIOUS GASTROINTESTINAL COMPLICATIONS: POOLED ANALYSIS OF 27,039 PATIENTS}

${ }^{1} \mathrm{G}$ Singh, ${ }^{2} \mathrm{G}$ Triadafilopoulos. ${ }^{1}$ Medicine/lmmunology and Rheumatology, Stanford University Medical Center; ${ }^{2}$ Section of Gastroenterology, Palo Alto Veterans Affairs Health Care System, Palo Alto, USA

\subsection{6/annrheumdis-2001.460}

Background Gastrointestinal (GI) complications are the most common adverse events associated with nonsteroidal anti-inflammatory drugs (NSAIDs). Although serious gastrointestinal complications, such as perforated ulcers and catastrophic bleeding, are uncommon, these events area.

Objectives We reviewed the incidence of serious upper GI (UGI) complications, including perforations, obstructions and hemodynamically-significant bleeds in a pooled data analysis of Meloxicam clinical trials that were at least 3 weeks in duration and included at least 20 patients per arm.

Methods Thirty-five trials with 27,309 patients on Meloxicam, comparator NSAID?s, or placebo were included in the analysis. Nearly 39\% (8109) patients were over age 65, and 1002 patients $(4 \%)$ had a previous history of perforation, ulcer or bleed. Cases of suspected GI events were ascertained based on pre-defined criteria. Case report forms and supporting details were blinded and submitted to an independent Endpoint Committee for adjudication.

Results A total of 448 potential cases were identified and sent for adjudication. The Endpoint Committee determined that 54 of these cases met the predefined criteria for a clinically significant event.

\begin{tabular}{|c|c|c|c|c|c|}
\hline & $\begin{array}{l}\text { No. } \\
\text { Patients }\end{array}$ & $\begin{array}{l}\text { Mean Exposure } \\
\text { (Days) }\end{array}$ & $\begin{array}{l}\text { Cummulative } \\
\text { Pt Years }\end{array}$ & $\begin{array}{l}\text { No. } \\
\text { Events }\end{array}$ & $\begin{array}{l}\text { Rate per } 100 \\
\text { pt years }\end{array}$ \\
\hline Placebo & 736 & 56 & 113 & 0 & 0 \\
\hline $\begin{array}{l}\text { Meloxicam } \\
7.5\end{array}$ & 10158 & 33 & 918 & 3 & 0.3 \\
\hline $\begin{array}{l}\text { Meloxicam } \\
15\end{array}$ & 2960 & 179 & 1451 & 9 & 0.6 \\
\hline $\begin{array}{l}\text { Meloxicam } \\
22.5\end{array}$ & 910 & 241 & 600 & 6 & 1.0 \\
\hline Diclofenac & 5464 & 35 & 524 & 9 & 1.7 \\
\hline Naproxen & 243 & 117 & 78 & 1 & 1.3 \\
\hline Piroxicam & 5371 & 41 & 603 & 16 & 2.7 \\
\hline
\end{tabular}

Conclusion The risk of clinically significant UGI events with meloxicam is dose-dependent and low at the recommended doses of $7.5 \mathrm{mg}$ and $15 \mathrm{mg}$.

\section{SAT0086 CARTILAGE DERIVED SEROLOGIC MARKERS AND RADIOGRAPHIC PROGRESSION OF KNEE OSTEOARTHRITIS}

M Olejarova, V Vilim, H Hulejova, J Gatterova, S Machacek, K Pavelka. Clinic of Rheumatology, Institute of Rheumatology, Prague, Czech Republic

\subsection{6/annrheumdis-2001.461}

\section{Background}

Objectives To determine relation between serum levels of cartilage derived markers (cartilage oligomeric matrix protein ? COMP, human gp 39 - chondrex, YKL-40) and radiographic progression in knee osteoarthritis (OA) patients.

Methods A cohort of 202 patients with symptomatic knee OA was introduced into the study and followed-up over the period of 3 years. Serum levels of markers were measured at the baseline and at the end of the study. COMP was measured using monoclonal antibodies, developed in our institute. Chondrex was measured using chondrex-kit (Biometra, USA). Radiographic progression was defined as reduction of joint space width (JSW) $>0.5 \mathrm{~mm}$ over the 3 years follow-up. Baseline serum COMP and chondrex levels were compared in patients with and without radiographic progression and correlated with maximal JSW reduction (one knee) and a total of JSW reductions from both knees.

Results Totally 118 patients completed the 3 years follow-up; 22 of them showed JSW reduction at least in one knee joint. The levels of both markers in progressive and non-progressive groups are summarised in the Table 1.

\begin{tabular}{lllll} 
Abstract SAT0086 Table 1 & \\
\hline & & $\begin{array}{l}\text { Progressive } \\
(\mathbf{n}=22)\end{array}$ & $\begin{array}{l}\text { Non-progressive } \\
(\mathbf{n}=\mathbf{9 6})\end{array}$ & $\mathbf{p}$ \\
\hline COMP (entry) & $\mathrm{ug} / \mathrm{ml}$ & $1.36 \pm 0.38$ & $1.18 \pm 0.41$ & $<0.05$ \\
COMP (3 years) & $\mathrm{ug} / \mathrm{ml}$ & $1.76 \pm 0.59$ & $1.18 \pm 0.35$ & $<0.05$ \\
Chondrex (entry) & $\mathrm{ng} / \mathrm{ml}$ & $93.35 \pm 81.59$ & $77.97 \pm 47.36$ & $\mathrm{NS}$ \\
Chondrex (3 years) & $\mathrm{ng} / \mathrm{ml}$ & $98.03 \pm 85.04$ & $83.35 \pm 52.81$ & $\mathrm{NS}$ \\
\hline
\end{tabular}


Maximal JSW reduction (one knee) significantly correlated with entry and final COMP levels $(\rho=0.201, \mathrm{p}<0.05, \rho=$ $0.187, \mathrm{p}<0.05)$; JSW reduction from both knees correlated with final COMP level $(\rho=0.162, \mathrm{p}<0.05)$; the correlation with entry COMP level nearly reached the significance level $(\mathrm{p}$ $=0.07)$. Chondrex levels did not correlate with JSW reduction at all.

Conclusion COMP could represent biochemical predictor of radiographic progression in knee OA. The possible predictive role of chondrex in radiographic progression of knee OA was not proven in this study.

\section{SAT0087 THE EFFECT OF MELOXICAM VERSUS USUAL CARE NSAIDS FOR THE TREATMENT OF OSTEOARTHRITIS IN A USUSAL CARE SETTING. THE RESULTS OF THE IMPROVE TRIAL}

${ }^{1} \mathrm{P}$ Gagnier, ${ }^{2} \mathrm{G}$ Singh, ${ }^{3} \|$ Reed, ${ }^{1} \mathrm{M}$ Kobe, ${ }^{1} \mathrm{P}$ Arnold, ${ }^{4} \mathrm{E}$ Hwang. ${ }^{1}$ Clinical Research; ${ }^{2}$ Medicine/lmmunology and Rheumatology, Stanford University Medical Center, Palo Alto, CA, USA; ${ }^{3}$ Rheumatology, Fallon Clinic, Worcester, MA, USA; ${ }^{4}$ Biometrics and Data Management, Boehringer Ingelheim Pharmaceuticals, Inc., Ridgefield

10.1136/annrheumdis-2001.462

Background Traditionally, NSAIDs have been the mainstays for managing symptoms of osteoarthritis (OA). While NSAIDs generally are considered to be effective in managing pain and inflammation, they frequently are associated with gastrointestinal side effects or lose their effectiveness leading to discontinuation of therapy or switching to another NSAID. These side effects can add significantly to the direct medical cost of managing the OA patient population. This suggests that there is dissatisfaction with current therapies on the part of the patient, physician or both. The time to discontinuation or change to another NSAID may be used as one measure that can examine the interrelated reasons for discontinuation, mainly efficacy and tolerability. Currently, there are no published randomised prospective studies that have examined the time to NSAID discontinuation; or NSAID switches and

Objectives The objective of this study was to compare the percentage of treatment successes or failures in patients randomised to meloxicam $7.5 \mathrm{mg}$ vs. usual care prescription NSAIDS in a variety of managed care settings (MCOs). A success was defined as a patient who started on their initially prescribed study NSAID and never received a different prescription NSAID during the trial. During the trial, the patient could have temporarily discontinued the new study prescription NSAID, restart the same drug and be considered a treatment success. A treatment failure was defined as a patient who started on an originally prescribed study NSAID and changed to another NSAID at any point during the trial.

Methods This was a multicenter, randomised, parallel-group, open-label trial of meloxicam $7.5 \mathrm{mg}$ versus usual care administration of prescription formulary NSAIDs for the treatment of patients with OA in a variety of MCO models. Patients with OA of the hip, knee, hand or spine were randomised to receive either meloxicam $7.5 \mathrm{mg}$ or any other prescription NSAID that they had not previously been treated with for their OA based on the patients formulary. The study was designed to mirror actual MCO practices and not add costly and unnecessary study-driven procedures at enrolment and throughout the observation period. The treatment/observation period was 6 months in duration and assessments were made to determine the reasons for permanent discontinuation from the initial prescription NSAIDs, number of
NSAID therapies, as well as the health care utilisation, efficacy and safety.

Results There were 1,321 patients entered into the trial and approximately $67 \%$ of the patients were female and $95 \%$ Caucasian. The mean age was approximately 64 years and the mean duration of OA was over 9 years. Rates of NSAID switching and efficacy will be discussed.

Conclusion The study was well accepted by physicians and patients.

\section{SAT0088 COST-BENEFIT ANALYSIS OF GLUCOSAMINE SULFATE USE}

${ }^{1} \mathrm{LG}$ Mantovani, ${ }^{1} \mathrm{~A}$ Belisari, ${ }^{2} \mathrm{C}$ Cristoforetti, ${ }^{2} \mathrm{G}$ Giacovelli, ${ }^{2} \mathrm{LC}$ Rovati. ${ }^{1}$ Centre of Pharmacoeconomy, University of Milan, Italy; ${ }^{2}$ Clinical Pharmacology Department, Rotta Research Lab. S.p. A., Monza Milan, Italy

\subsection{6/annrheumdis-2001.463}

Background Osteoarthritis (OA) is a disabling and costly disease (see Belisari's and Mantovani's abstract). Glucosamine sulfate has shown to be effective in reducing the severity of OA as measured through the Lequesne index (LI).

Objectives To evaluate the the pharmacoeconomic profile of Glucosamine sulfate in Italy.

Methods Cost-benefit analysis of glucosamine sulfate use in the context of the Italian society. We compared 2 different pharmacological interventions in OA patients: piroxicam vs. glucosamine sulfate. We considered direct medical costs (e.g. treatment), direct non-medical (e.g. home adaptation, transport, etc.) and indirect (e.g. wage losses) costs. Costs are expressed in Euros 2000. Benefits were measured on the results of a reference randomised clinical trial. They were expressed in terms of LI score reduction, and were turned into monetary terms using the equation estimated in the study by Belisari and Mantovani, which shows a significant association between severity of the disease and costs (higher costs in more severe patients).

Results Although glucosamine sulfate therapy cost is higher than piroxicam one (81 vs. 33 Euros, the intervention with glucosamine sulfate resulted in a potential net saving of almost 11 Euro/patient in 90 days and 110 Euros/patient in 150 days attributable to its higher efficacy.

Conclusion Based on our estimates, glucosamine sulfate has a favourable cost benefit profile compared to piroxicam.

\section{REFERENCE}

1 Rovati LC. Osteoarthritis Cartilage 1997;5(Suppl A):72

\section{SAT0089 ROFECOXIB PROVIDES SUPERIOR RELIEF OF SYMPTOMS OF OSTEOARTHRITIS (OA) COMPARED TO CELECOXIB}

${ }^{1} T J$ Schnitzer, ${ }^{2} \mathrm{AJ}$ Kivitz, ${ }^{3} \mathrm{M}$ Greenwald, ${ }^{4} \mathrm{RM}$ Fleischmann, ${ }^{5} \mathrm{D}$ Matzura-Wolfe, ${ }^{5} \mathrm{AB}$ Polis, ${ }^{5} \mathrm{ME}$ Dixon, ${ }^{5} \mathrm{TW}$ Dobbins, ${ }^{5} \mathrm{GP}$ Geba. ${ }^{1}$ Northwestern University, Chicago IL, USA; ${ }^{2}$ Altoona Center for Clinical Research, Ducansville, PA, USA; ${ }^{3}$ Advances in Medicine, Rancho Mirage, CA, USA; ${ }^{4}$ Metroplex Clinical Research, Dallas, TX, USA; ${ }^{5}$ Merck and Co., Inc., West Point $P A, U S A$

\subsection{6/annrheumdis-2001.464}

\section{Background}

Objectives We performed a randomised, double-blind, clinical trial to evaluate the efficacy and safety of rofecoxib and celecoxib at highest indicated once daily doses in osteoarthritis. 